\title{
The Low-Affinity Neurotrophin Receptor p75 Regulates the Function But Not the Selective Survival of Specific Subpopulations of Sensory Neurons
}

\author{
Cheryl L. Stucky and Martin Koltzenburg \\ Department of Neurology, University of Würzburg, D-97080 Würzburg, Germany
}

Mice with a targeted deletion of the low-affinity neurotrophin receptor p75 (p75-/-) exhibit a 50\% loss of large- and smalldiameter sensory neurons in the dorsal root ganglion. Using neurophysiological recording techniques, we now show that p75 is not required for the survival of specific, functionally defined subpopulations of sensory neurons. Rather, p75-/mice exhibit losses of neurons that subserve nociceptive as well as non-nociceptive functions. The receptive properties of large myelinated afferent fibers were normal in $\mathrm{p} 75-/-$ mice.
However, the receptive properties of subpopulations of afferent fibers with thin myelinated or unmyelinated axons were strikingly impaired in mice lacking p75. Furthermore, the presence of p75 is required for normal mechanotransduction in $C$ fibers and D-hair receptors and normal heat sensitivity in A-fiber nociceptors.

Key words: NGF; BDNF; NT-3; NT-4; nociceptor; dorsal root ganglion; apoptosis; mechanosensation; electrophysiology
Neurotrophins play a critical role in the differentiation, development, and survival of sensory neurons. The biological effects of neurotrophins are mediated by two distinct classes of receptors. High-affinity binding of neurotrophins is mediated by the tyrosine kinase (trk) family of receptors, in which each neurotrophin selectively binds to a specific trk receptor (Barbacid, 1994). All of the neurotrophins, however, also bind with low affinity to the non-trk, transmembrane protein p75 (Radeke et al., 1987; Rodríguez Tébar et al., 1990, 1992; Hallböök et al., 1991). Trk receptors are expressed on distinct populations of sensory neurons, because trkA is expressed predominantly on small-diameter neurons, whereas trkC is localized to large-diameter neurons $(\mathrm{Mu}$ et al., 1993; McMahon et al., 1994; Wright and Snider, 1995). The p75 receptor, in contrast, has a much more widespread distribution, because $\sim 50 \%$ of all sensory neurons of different cell sizes express p75 mRNA (Carroll et al., 1992; Schecterson and Bothwell, 1992; Wright and Snider, 1995). Studies using transgenic mice that have deletions for specific neurotrophins or specific trk receptors indicate that the survival of functionally distinct subpopulations of peripheral sensory neurons depends on specific neurotrophins. For example, NGF and its high-affinity trkA receptor are required for the survival of nociceptive sensory neurons (Crowley et al., 1994; Smeyne et al., 1994), whereas NT-3 and trkC are required for the survival of non-nociceptive mechanoreceptors (Ernfors et al., 1994; Fariñas et al., 1994; Klein et al., 1994; Airaksinen et al., 1996).

Little is known about the specificity of p75 in regulating the survival and function of classes of sensory neurons. Given that all of the neurotrophins bind p75 and given the widespread distribution of p75 among sensory neurons, an important question is

\footnotetext{
Received Nov. 27, 1996; revised Feb. 21, 1997; accepted March 14, 1997.

This work was supported by the Deutsche Forschungsgemeinschaft, Sonderforschungsbereich 353 .

Correspondence should be addressed to Dr. Martin Koltzenburg, Department of Neurology, University of Würzburg, Josef-Schneider-Strasse 11, D-97080 Würzburg, Germany.

Copyright (C) 1997 Society for Neuroscience $\quad 0270-6474 / 97 / 174398-08 \$ 05.00 / 0$
}

whether p75 affects the survival and function of all subtypes of sensory neurons equally or whether it regulates specific subpopulations. Morphological studies show that transgenic mice that lack p75 (p75-/-) have macroscopically smaller dorsal root ganglia (Lee et al., 1992; Bergmann et al., 1997), and unbiased stereological counting methods have determined that there is a $50 \%$ loss in the total number of neurons in the dorsal root ganglia of p75-/- mice, affecting both large- and small-diameter neurons (M. Dreetz, T. Tandrup, M. Koltzenburg, and J. Jakobsen, unpublished observations) (see also Curtis et al., 1995; Diamond et al., 1995). Immunohistochemical studies indicate that p75-/mice display reduced density of cutaneous innervation by both nociceptive and non-nociceptive sensory fibers (Lee et al., 1992; Bergmann et al., 1997). In agreement, behavioral studies show that p75-/- mice exhibit decreased responsiveness to noxious thermal and mechanical stimuli (Lee et al., 1992; Bergmann et al., 1997), suggesting that nociceptive sensory neurons may be lost or functionally impaired. On the other hand, sensory-motor deficits in $75-/-$ mice indicate that the survival of some nonnociceptive, myelinated mechanoreceptors may also be compromised (Lee et al., 1995). However, p75-/- mice exhibit no selective loss of subpopulations of dorsal root ganglion neurons that can be recognized by immunohistochemical staining for trkA, calcitonin gene-related peptide (CGRP), the lectin IB4, or the neurofilament antibody RT97 (Bergmann et al., 1997).

Thus, neither behavioral nor histological techniques have unequivocally revealed whether p75 is required for the survival or function of specific populations of sensory neurons. Here, we have used the only technique currently available that permits direct analysis of the prevalence and function of defined populations of sensory neurons. We used standard electrophysiological techniques to analyze single cutaneous sensory neurons and their response properties to natural stimuli.

\section{MATERIALS AND METHODS}

Animals. Breeding pairs of homozygous transgenic mice lacking p75 (p75-/-) (Lee et al., 1992) were obtained from Jackson Laboratories 
A

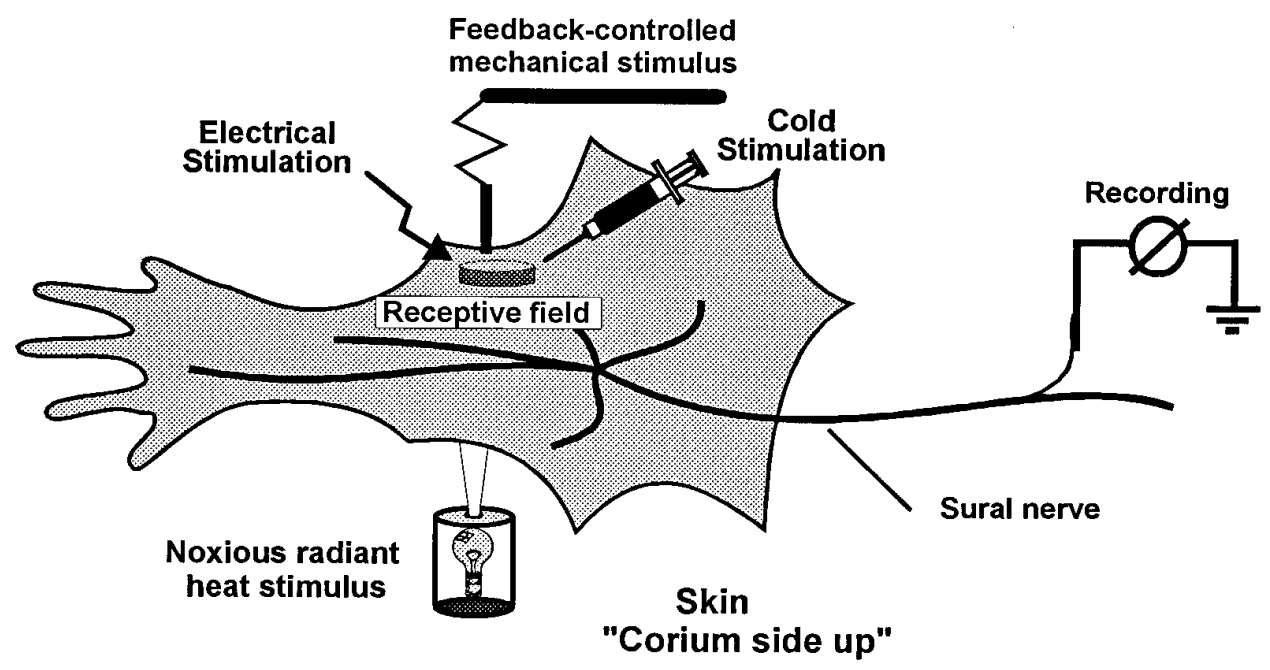

B

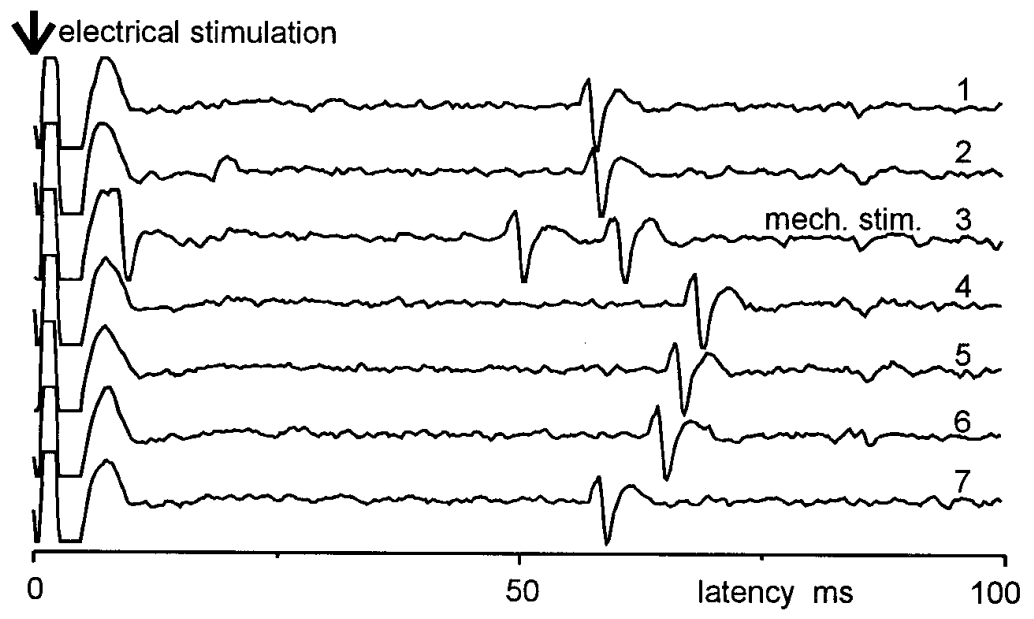

Figure 1. $A$, In vitro skin-nerve preparation. $B$, Electrical stimulation procedure used to "mark" $\mathrm{C}$ fibers. C fibers have a stable latency after supramaximal electrical stimulation (3 sec interstimulus interval) of the receptive field (traces 1-2). However, after adequate activation of the fiber with a mechanical stimulus (trace 3, mech. stim.), there is a typical shift in the latency of the electrically evoked response that recovers gradually (traces $4-7$ ). The shift in latency and recovery indicates that both the electrically and the mechanically evoked action potentials were evoked from the same unit.

(Bar Harbor, ME). Balb/c mice, which are part of the genetic background of p $75-/-$ mice, were used as the p $75+/+$ control and were obtained from Charles River Wiga, Sulzfeld, Germany. For both groups, adult mice of both sexes were used, and age of mice ranged from 8 to 50 weeks and body weight ranged from 14 to $34 \mathrm{gm}$.

Neurophysiological recordings. This study was performed using the in vitro skin-nerve preparation described previously (Airaksinen et al., 1996). Briefly, the hairy skin of the hindlimb was dissected together with the sural nerve, placed corium side up in an organ bath, and superfused with oxygen-saturated, synthetic interstitial fluid containing (in $\mathrm{mM}$ ): 123 $\mathrm{NaCl}, 3.5 \mathrm{KCL}, 0.7 \mathrm{MgSO}_{4}, 1.7 \mathrm{NaH}_{2} \mathrm{PO}_{4}, 2.0 \mathrm{CaCl}_{2}, 9.5$ sodium gluconate, 5.5 glucose, 7.5 sucrose, and 10 HEPES, $\mathrm{pH}$ of $7.45 \pm 0.05$, at a temperature of $32^{\circ} \pm 0.5^{\circ} \mathrm{C}$ (Fig. $1 \mathrm{~A}$ ). Single afferent fibers were recorded extracellularly from the desheathed nerve using gold wire electrodes. Using a low-noise differential amplifier, action potentials were acquired on a PC and later analyzed with a custom-made template-matching program (Forster and Handwerker, 1990). Units were first identified by manual probing with a blunt glass rod. The conduction velocity of each unit was determined by stimulating the receptive field electrically with supramaximal square wave pulses of $0.1-1.0 \mathrm{msec}$ duration using a Teflon-coated steel electrode (1-5 M $\Omega$ impedance, $300 \mu \mathrm{m}$ shaft diameter, 5-10 $\mu \mathrm{m}$ uninsulated tip diameter). Units conducting faster than 10 $\mathrm{m} / \mathrm{sec}$ were considered to be large myelinated $(\mathrm{A} \beta)$ fibers, units conducting slower than $1.2 \mathrm{~m} / \mathrm{sec}$ were unmyelinated $\mathrm{C}$ fibers, and units conducting between 1.2 and $10 \mathrm{~m} / \mathrm{sec}$ were thin myelinated $(\mathrm{A} \delta$ ) fibers (Airaksinen et al., 1996) (M. Koltzenburg, C. L. Stucky, and G. R. Lewin, unpublished results). For $A \beta$ and $A \delta$ fibers, the identity of the electrically and mechanically evoked action potentials was determined to be the same if the shape of the respective action potentials was identical. The identity of electrically and naturally evoked activity in $C$ fibers was verified by a standard marking procedure (Fig. $1 B$ ). Mechanical sensitivity was determined using calibrated von Frey filaments $(0.8 \mathrm{~mm}$ tip diameter, 1-362 $\mathrm{mN}$ range of force) and sustained force stimuli (200 msec rise time, $10 \mathrm{sec}$ duration of force plateau) applied by a computer-driven, feedbackcontrolled stimulator (5-300 $\mathrm{mN}$ range of force). Data were analyzed for $11 \mathrm{sec}$ beginning with the onset of the probe. A linear heat ramp 
Table 1. Von Frey thresholds

\begin{tabular}{|c|c|c|c|c|c|c|}
\hline \multirow[b]{2}{*}{ Fiber type } & \multicolumn{2}{|l|}{ Median } & \multicolumn{2}{|c|}{ Interquartile range } & \multicolumn{2}{|l|}{$n$} \\
\hline & $\mathrm{p} 75+/+$ & p $75-/-$ & $\mathrm{p} 75+/+$ & $\mathrm{p} 75-/-$ & $\mathrm{p} 75+/+$ & $\mathrm{p} 75-/-$ \\
\hline SA & 1.0 & 1.0 & $1.0-1.5$ & $1.0-3.4$ & 12 & 12 \\
\hline RA & 1.0 & 1.0 & $1.0-2.0$ & $1.0-1.0$ & 17 & 20 \\
\hline $\mathrm{AM}$ & 4.0 & 5.6 & $4.0-8.0$ & $4.0-8.0$ & 37 & 34 \\
\hline D hair & 1.0 & 1.0 & $1.0-1.0$ & $1.0-1.0$ & 11 & 33 \\
\hline $\mathrm{C}$ fiber & 5.6 & 8.0 & $4.0-11.2$ & $5.6-11.2$ & 23 & 31 \\
\hline
\end{tabular}

$\left(32^{\circ}-47^{\circ} \mathrm{C}\right.$ in $\left.15 \mathrm{sec}\right)$ was applied by a feedback controlled lamp focused through the translucent bottom of the organ bath onto the epidermal side of the skin, and temperature was measured at the corium side by a thermocouple inserted into the skin. Cold stimuli were given by isolating the receptive field with a metal ring and applying a bolus injection of ice-cold synthetic interstitial fluid for $5 \mathrm{sec}$, resulting in a peak temperature of $4^{\circ}-8^{\circ} \mathrm{C}$. Care was taken to avoid mechanical stimulation during the thermal stimuli. A fiber was considered to respond to heat or cold if three or more action potentials were evoked during the stimulation.

\section{RESULTS}

We recorded from 230 cutaneous afferent fibers in the sural nerve which innervates the lateral part of the hairy skin of the hindpaw. Of these fibers, 130 were studied in p75-/- mice $(n=27)$, and 100 were studied in p75 $+/+$ mice $(n=17)$ (Fig. $1 A)$. Myelinated fibers were classified as described previously into four subpopulations based on their conduction velocity and adaptation properties to constant force stimuli (Airaksinen et al., 1996). All large myelinated fibers $(\mathrm{A} \beta)$ had low mechanical thresholds and were classified as either slowly adapting $(S A)$ or rapidly adapting $(R A)$ mechanoreceptors (Fig. $2 A$ ). Thin myelinated fibers (A $\delta)$ were classified as either high-threshold A-mechanonociceptors $(A M)$ or sensitive D-hair receptors (Fig. $2 B$ ). Here, we have also studied unmyelinated fibers in mice for the first time (Fig. $1 B$ ). As shown previously in the rat (Kress et al., 1992), unmyelinated C fibers were tested for their response properties to mechanical stimuli and then classified further by their responsiveness to noxious thermal stimuli (Fig. 2C).

All types of functionally defined cutaneous sensory neurons present in $\mathrm{p} 75+/+$ mice also were found in $\mathrm{p} 75-/-$ mice, indicating that there is no complete loss of any functionally defined population of sensory neurons in $\mathrm{p} 75-/-$ mice. The stimulusresponse functions of the sensory fibers in the inbred wild-type mice used here were not different from those in another outbred wild-type strain (Airaksinen et al., 1996). This indicates that there is little variability in the electrophysiological parameters of afferent fibers in different strains of wild-type mice.

\section{Low-threshold $A \beta$ mechanoreceptors are normal in p75-I- mice}

The prevalence of both low-threshold SA and RA mechanoreceptors in p $75-/-$ mice was normal. Thirty-eight percent of $\mathrm{A} \beta$ fibers in $\mathrm{p} 75-/-$ mice were SA, compared with $41 \%$ in $\mathrm{p} 75+/+$ mice. The remainder of the $A \beta$ fibers in both groups were RA fibers (Fig. 3). Furthermore, the mechanical sensitivity of both SA and RA mechanoreceptors was unaltered in p75-/- mice. First, there were no differences in the von Frey thresholds of either SA or RA mechanoreceptors in $\mathrm{p} 75-/-$ mice, compared with wild-type mice (Table 1). Second, the stimulus-response functions, which correlate force to discharge frequency, were unaltered for both SA and RA fibers in p75-/- mice (Fig. $4 A, B$ ). SA fibers in both p $75-/-$ and p $75+/+$ mice encoded the stimulus intensity in the lower range of intensities used $(5-20 \mathrm{mN})$ and saturated at higher stimulus intensities. RA fibers in both groups exhibited a discharge at all stimulus intensities and responded only at the onand offset of the stimulus.

\section{Nociceptors in p75-/- mice are reduced in number and impaired in function}

In contrast to low-threshold $\mathrm{A} \beta$ mechanoreceptors, which were unaltered in p75-/- mice, nociceptive sensory neurons in p75-/- mice displayed deficits in several aspects. First, the prevalence of AM nociceptors was reduced significantly from $68 \%$ in p $75+/+$ mice to $42 \%$ in p $75-/-$ mice $\left(p<0.05, \chi^{2}\right.$ test) (Fig. 3). Second, whereas the mechanical sensitivity of the remaining AM nociceptors in p $75-/-$ mice was normal (Table 1 , Fig. $4 C$ ), the heat sensitivity of these nociceptors was reduced significantly. None of the AM fibers in p75-/- mice responded to heat, in contrast to $26 \%$ of AM nociceptors in p75+/+ mice that were heat-sensitive ( $p<0.05, \chi^{2}$ test) (Table 2). However, there was no difference in the sensitivity of AM fibers to cold stimuli in p75-/and p $75+/+$ mice (Table 2 ).

There was no significant difference in the proportion of thermally sensitive unmyelinated fibers, because $64 \%$ of $\mathrm{C}$ fibers in p $75-/-$ mice responded to heat, compared with $41 \%$ in $\mathrm{p} 75+/+$ animals $\left(p>0.1, \chi^{2}\right.$ test) (Table 2$)$. There was a marginally significant difference in the mean conduction velocity of $\mathrm{C}$ fibers between p $75-/-$ mice $(0.58 \pm 0.03 \mathrm{~m} / \mathrm{sec} ; n=32)$ and $\mathrm{p} 75+/+$ mice $(0.69 \pm 0.05 \mathrm{~m} / \mathrm{sec} ; n=23)$. However, this small difference would not account for the slightly but not significantly increased proportion of $\mathrm{C}$ fibers in $\mathrm{p} 75-/-$ mice that responded to heat, because the response properties of $\mathrm{C}$ fibers do not correlate with conduction velocities (Kress et al., 1992). There also was no difference between the two groups of mice in the heat threshold or average number of action potentials evoked by the standard heat stimulus $(p>0.05$, Student's $t$-test) (Table 2). Furthermore, there was no difference in the proportion of $\mathrm{C}$ fibers that responded to cold stimuli (Table 2). However, the mechanical sensitivity of unmyelinated $\mathrm{C}$ fibers in p $75-/-$ mice was reduced significantly (Fig. 4E). At all stimulus intensities tested, C fibers in p75-/mice discharged $\sim 50 \%$ fewer action potentials to mechanical stimuli than $\mathrm{C}$ fibers in p $75+/+$ mice (Fig. $4 E$ ). Whereas $\mathrm{C}$ fibers in $\mathrm{p} 75+/+$ mice encoded the strength of the mechanical stimulus throughout the range of stimuli, $\mathrm{C}$ fibers in $\mathrm{p} 75-/-$ mice saturated at much lower forces $(100 \mathrm{mN})$. For an individual stimulus, the reduced mechanical responsiveness of $\mathrm{C}$ fibers was present for the duration of the sustained stimulus (Fig. 5A).

\section{Non-nociceptive D-hair receptors in p75-/- mice have reduced mechanical sensitivity}

In contrast to low-threshold SA and RA mechanoreceptors, which were normal in both their prevalence and their responsiveness to 
A

\section{Slowly adapting \\ mechanoreceptor}

(SA)

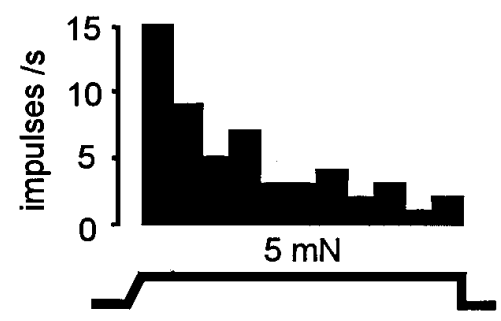

B

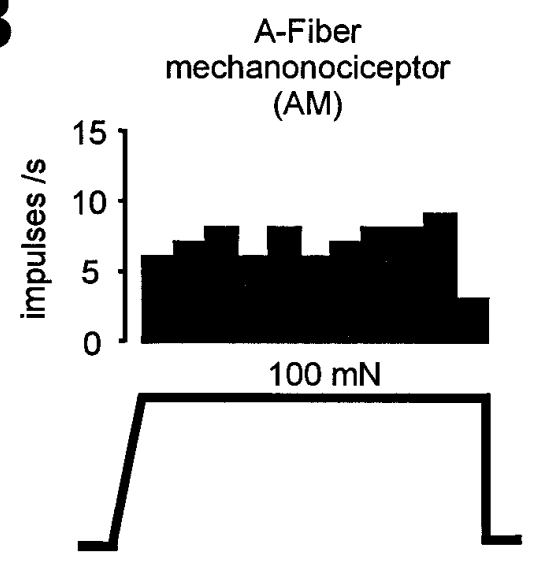

Rapidly adapting

mechanoreceptor

(RA)

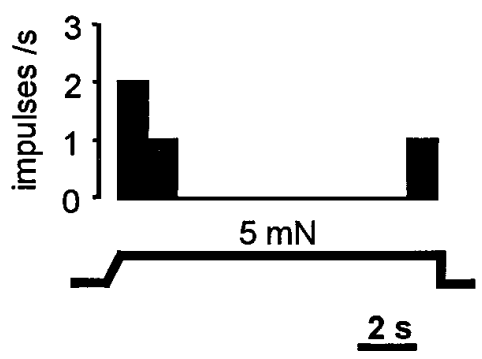

$2 s$

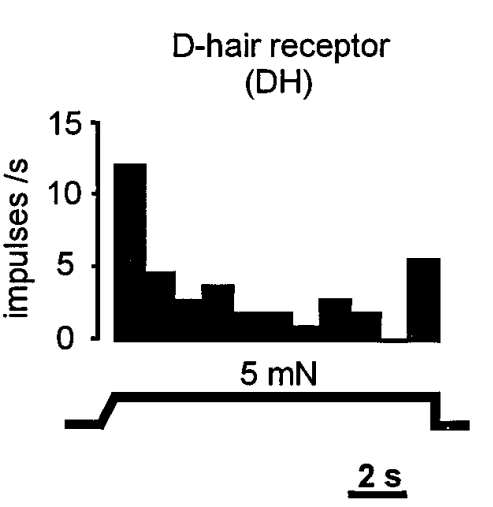

C

Response to mechanical force

$$
\text { 高 }
$$

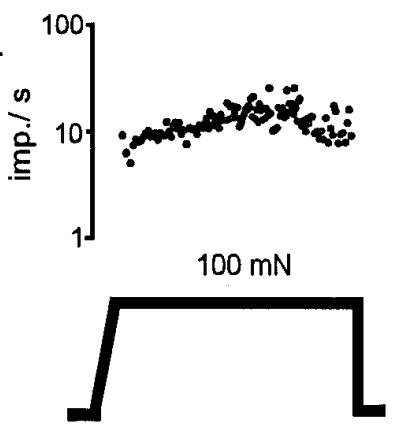

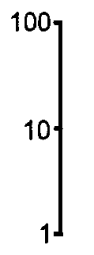

Response to heat

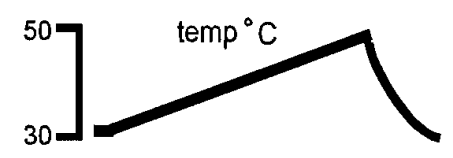

Response to cold

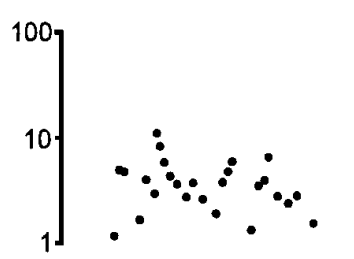

Cold
Figure 2. Representative examples of response properties of cutaneous afferent fibers. $A$, Among the $\mathrm{A} \beta$ fibers, SA mechanoreceptors fire tonically throughout a constant low-intensity force stimulus, whereas RA fibers fire only at the on- and offset of the stimulus. Histograms (bin width $=1 \mathrm{sec}$ ) indicate impulses/sec during a sustained mechanical stimulus. $B$, Among A $\delta$ fibers, A-fiber nociceptors require highintensity mechanical stimuli for activation and fire tonically throughout the stimulus. In contrast, D-hair receptors have very low thresholds for activation $(<1.0 \mathrm{mN})$ and fire at high frequencies at the on- and offset of the stimulus. $C$, Representative examples of responses of a $\mathrm{C}$ fiber to mechanical, heat, and cold stimuli are illustrated. Response is plotted as instantaneous frequency, where each dot represents one action potential. mechanical stimuli, low-threshold D-hair receptors in p75-/mice showed significantly reduced responsiveness to mechanical stimuli at all stimulus intensities tested (Fig. 4D). The reduced frequency of firing occurred primarily within the first 2 sec after onset of the stimulus, the time when peak firing of D-hair receptors occurs with constant force mechanical stimuli (Fig. 5B).

\section{DISCUSSION}

Adult mice that lack the low-affinity neurotrophin receptor have all types of functionally defined cutaneous primary afferent neurons found in wild-type mice. In spite of the $50 \%$ loss in total sensory neurons in p75-/- mice, no functionally defined subtype of sensory neuron is preferentially lost. Furthermore, we show that the specific deficits in populations of sensory neurons in p75-/- mice are losses in function. C-fiber nociceptors and low-threshold D-hair receptors have reduced mechanical responsiveness, and AM nociceptors are completely heat-insensitive. Thus, p75 is not required for the survival of a specific, functionally defined subpopulation of sensory neurons; however, p75 is important for the mechanical responsiveness of $\mathrm{C}$ fibers and $\mathrm{D}$-hair receptors and the heat sensitivity of A-fiber nociceptors. 


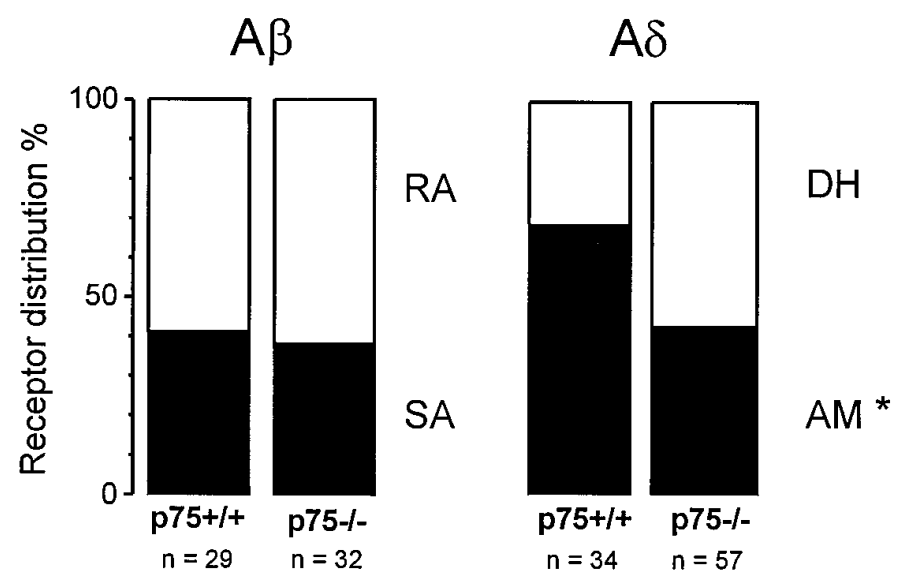

Figure 3. Prevalence of functionally defined sensory receptors among A $\beta$ and $\mathrm{A} \delta$ fibers. The asterisk indicates that the number of fibers in $\mathrm{p} 75-/-$ mice is significantly different from that for $\mathrm{p} 75+/+$ mice; $p<0.05, \chi^{2}$ test.

Table 2. Thermal responsiveness of nociceptors

$\mathrm{AM}$

\begin{tabular}{lll}
\hline & $\mathrm{p} 75+/+$ & $\mathrm{p} 75-/-$ \\
\hline $\begin{array}{l}\text { \% Units responding } \\
\text { to heat }\end{array}$ & $26(5 / 19)$ & $0(0 / 17)^{*}$ \\
$\begin{array}{l}\text { Threshold for heat } \\
\text { response }\left({ }^{\circ} \mathrm{C}\right)\end{array}$ & $42.4 \pm 2.4$ & - \\
$\begin{array}{l}\text { Units responding } \\
\text { to cold }\end{array}$ & $10(1 / 10)$ & $33(1 / 3)$ \\
\hline
\end{tabular}

C fiber

\begin{tabular}{lll}
\hline & $\mathrm{p} 75+/+$ & $\mathrm{p} 75-/-$ \\
\hline $\begin{array}{l}\text { \% Units responding } \\
\text { to heat }\end{array}$ & $41(7 / 17)$ & $64(14 / 22)$ \\
$\begin{array}{l}\text { Threshold for heat } \\
\text { response }\left({ }^{\circ} \mathrm{C}\right)\end{array}$ & $38.8 \pm 1.8$ & $38.4 \pm 1.0$ \\
$\begin{array}{l}\% \text { Units responding } \\
\text { to cold }\end{array}$ & $30(3 / 10)$ & $36(4 / 11)$
\end{tabular}

*Percent of fibers in p75-/- animals significantly different from that in p $75+/+$ animals $\left(p<0.05, \chi^{2}\right.$ test $)$. Threshold values are given as mean \pm SEM.

\section{Nociceptive and non-nociceptive sensory neurons are lost in p75-/- mice}

Unbiased stereological counting methods have shown that p75-/- mice exhibit a $50 \%$ loss in the total number of sensory neurons in the dorsal root ganglion, including both large- and small-diameter neurons (M. Dreetz, T. Tandrup, M. Koltzenburg, and J. Jakobsen, unpublished observations). Furthermore, immunohistochemical studies show that these mice have markedly reduced innervation of the skin by both nociceptive and nonnociceptive sensory fibers (Bergmann et al., 1997). Because $\sim 50 \%$ of neurons in the dorsal root ganglion express the p75 receptor (Carroll et al., 1992; Schecterson and Bothwell, 1992; Wright and Snider, 1995), one obvious possibility is that all p75-expressing neurons are lost in p75-/- mice. However, histological studies suggest that this is not the case. In rat, virtually all trkA-expressing sensory neurons and all CGRP-containing neurons also express p75, whereas IB4-expressing neurons do not (Wright and Snider, 1995). Yet there is no change in the percentages of trkA-positive,
CGRP-positive, or IB4-positive neurons in p75-/- mice (Bergmann et al., 1997). Although we cannot completely exclude the possibility that there may be independent changes in the distribution of these markers during development, these data suggest that both p75-positive and p75-negative neurons are lost equally.

Another possible explanation for the $50 \%$ cell loss in p75-/mice is that only nociceptive neurons are lost. The survival of nociceptors depends on the presence of NGF and its high-affinity receptor trkA (Ruit et al., 1992; Crowley et al., 1994; Smeyne et al., 1994). Sensory neurons cultured from p75-/- mice show decreased NGF-dependent survival (Lee et al., 1994). Furthermore, p75-/- mice display reduced behavioral responses to noxious thermal and mechanical stimuli (Lee et al., 1992; Bergmann et al., 1997). However, two pieces of evidence indicate that preferential loss of nociceptors does not account for the cell death. First, in p75-/- mice, there is no selective loss of trkA-, CGRP-, or IB4-expressing sensory neurons, which are likely to be nociceptors (McMahon et al., 1994; Averill et al., 1995; Wright and Snider, 1995; Bergmann et al., 1997). Second, although we observed a slight reduction in the prevalence of AM nociceptors among the thin myelinated fiber population, this cannot account for the $50 \%$ loss of cells in the dorsal root ganglion, because all thin myelinated fibers together make up only $10 \%$ of the total fibers that innervate the skin (Albers et al., 1996).

Given that p75-/- mice do not exhibit a selective loss of nociceptors, another possibility is that a selective loss of nonnociceptive neurons may account for the $50 \%$ cell death. We studied three different populations of low-threshold nonnociceptive neurons, including SA fibers, RA fibers, and D-hair receptors, and we found that no selective loss of any of these fiber types occurred in p75-/- mice. We have shown in previous studies that NT-3 is crucial for the survival of SA fibers, whereas NT-3 and NT-4 both support survival of D-hair receptors (Airaksinen et al., 1996; Stucky et al., 1996). Therefore, our results conclude that the p75 receptor plays no critical role in the NT-3or NT-4-mediated survival of SA fibers or D-hair receptors. Together, the electrophysiological and histological data show that both nociceptive and non-nociceptive sensory neurons are lost in p75-/- mice. One mechanism by which this nonselective loss in sensory neurons may occur is if neurons are lost before they are committed to their functional phenotypes.

\section{Specific functionally defined subpopulations of sensory neurons in p75-/- mice have losses in function}

The data presented in this paper demonstrate that although no selective losses of specific populations of sensory neurons occur in p75-/- mice, important functional changes occur in specific subtypes of sensory neurons. This could mean that p 75 plays a key role in mediating the function of sensory neurons after they have differentiated into functional phenotypes. Large myelinated lowthreshold SA and RA fibers in p75-/- mice were completely normal in function. We have shown previously that BDNF is required for the normal mechanotransduction of SA fibers (Koltzenburg et al., 1995). Therefore, our results show that p75 is not required for the BDNF-mediated mechanical function of SA fibers or the mechanical function of RA fibers.

Because none of the AM fibers responded to heat in $\mathrm{p} 75-/-$ mice, p75 is required for the expression of heat sensitivity in AM nociceptors. The loss of heat-sensitive AM fibers could be attributable either to the selective death of these fibers or to a phenotype switch. Because no specific marker for heat-sensitive AM fibers is 
A
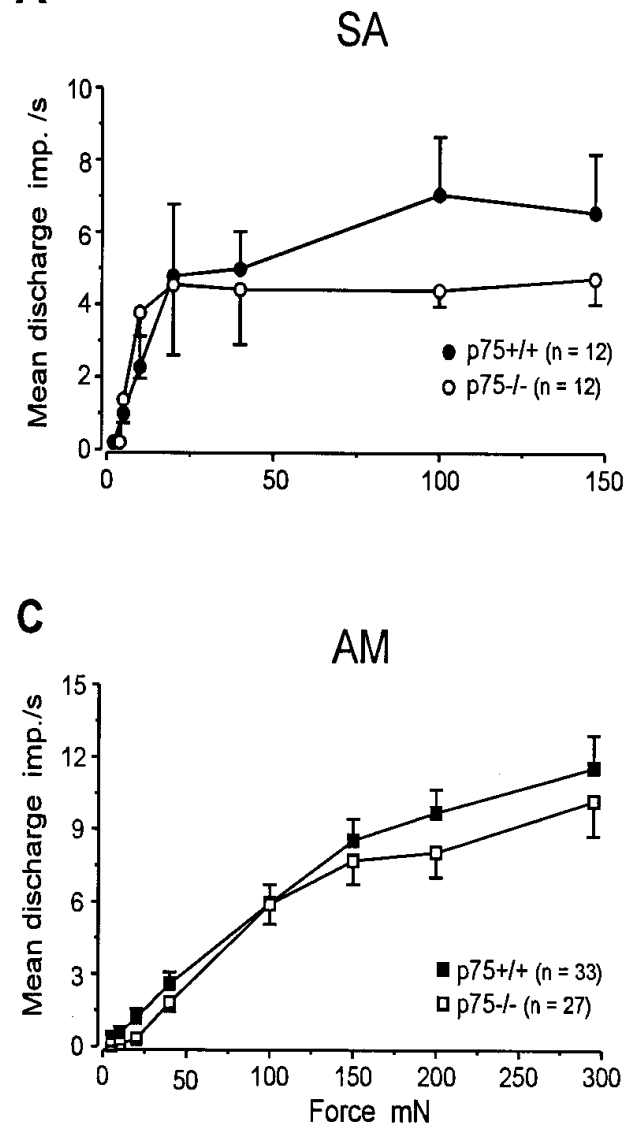

B

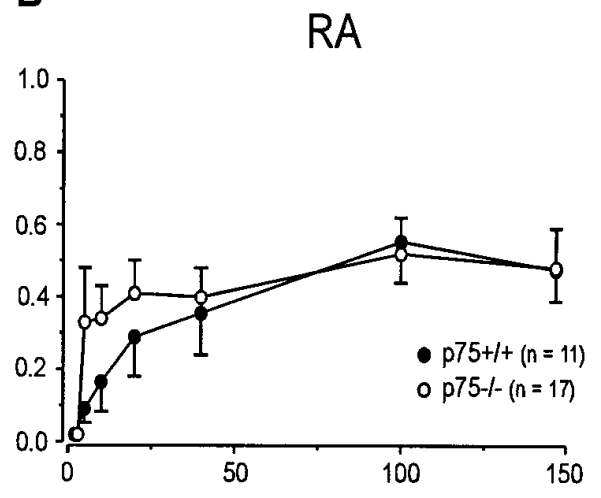

E

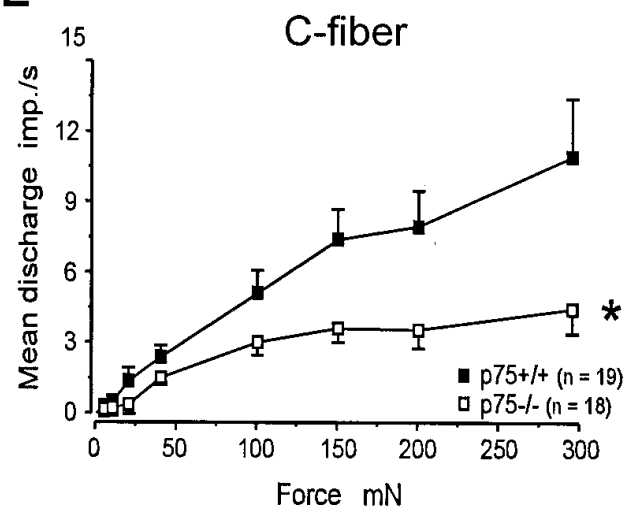

Figure 4. Stimulus-response functions of cutaneous fibers to constant force stimuli. There were no statistically significant differences in the mechanical stimulus-response functions of SA $\left(F_{(1,139)}=0.44, p>\right.$ $0.5)$, RA $\left(F_{(1,158)}=2.24, p>0.1\right)$, or AM $\left(F_{(1,458)}=2.41, p>0.1\right)$ fibers between p $75-/-$ and p75+/+ mice. However, the stimulus-response functions for D-hair receptors $\left(F_{(1,208)}=30, p<0.001\right)$ and $\mathrm{C}$ fibers $\left(F_{(1,277)}=16.5, p<0.001\right)$ were significantly reduced in p $75-/-$ mice, compared with $\mathrm{p} 75+/+$ mice. Values indicate mean frequency \pm SEM of action potentials per second for all fibers. Statistical differences were tested using ANOVA.

available at this time, we cannot exclude the possibility that there may be selective cell death of heat-sensitive AM fibers. However, we favor the explanation that the heat-sensitive AM fibers in p75-/- mice underwent a phenotype switch, because other studies have shown that AM nociceptors undergo a permanent phenotype switch to D-hair receptors after postnatal treatment with antibodies that neutralizes endogenous NGF (Ritter et al., 1991; Lewin et al., 1992). Additional evidence from our laboratory suggests that the ligand responsible for the change in AM fibers in p75-/- mice is NGF, because NT-3, BDNF, or NT-4 are not required for the survival or function of AM nociceptors (Koltzenburg et al., 1995; Airaksinen et al., 1996; Stucky et al., 1996). Furthermore, the heat sensitivity of A $\delta$ fibers is not a constant feature of this subpopulation of fibers, but instead is quite variable. For example, after inflammation of the skin, many AM fibers become heat sensitive (Meyer and Campbell, 1981; Thalhammer and LaMotte, 1982), and NGF has been implicated in this process. In adult animals, application of exogenous NGF induces many AM fibers to become responsive to heat within seconds (Rueff and Mendell, 1995; Tal et al., 1996). Conversely, sequestration of NGF by a trkA-IgG fusion molecule prevents the sensitization of nociceptors to heat in inflamed skin (Bennett et al., 1996). Because p75 has been shown to enhance the affinity of trkA for NGF (Hempstead et al., 1991), p75 may regulate the NGF-dependent postnatal phenotype of AM fibers by enhancing NGF signaling.

The mechanical transduction in two populations of neurons was impaired in p75-/- mice. C-fiber nociceptors, which respond tonically to high-threshold stimuli, and non-nociceptive D-hair receptors, which respond only to the on- or offset of a stimulus, 


\section{A}

Figure 5. Mean discharge frequency per second during supramaximal mechanical stimuli for $\mathrm{C}$ fibers and D-hair receptors. $A, \mathrm{C}$ fibers in p75-/- mice exhibited reduced frequency of firing throughout a supramaximal stimulus, compared with p75 $+/+$ mice. Bars (bin width $=1 \mathrm{sec}$ ) indicate the mean impulses/sec evoked in response to a $200 \mathrm{mN}$ sustained stimulus for all $\mathrm{C}$ fibers tested. $B$, D-hair receptors in p75-/- mice exhibited reduced frequency of firing, primarily during the first $2 \mathrm{sec}$ after onset of the stimulus. Bars indicate the mean impulses/ sec evoked in response to a $100 \mathrm{mN}$ sustained stimulus for all D-hair receptors tested.

\section{C-fibers}

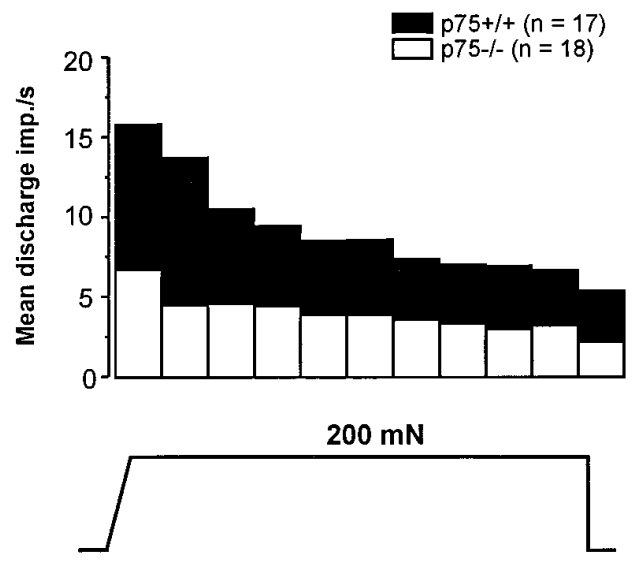

B

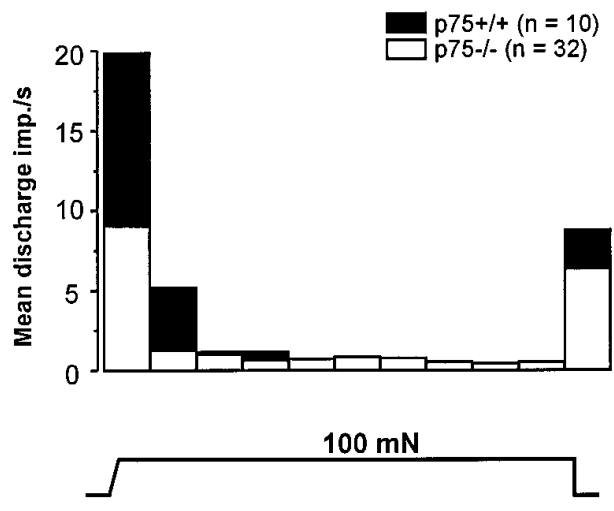

both exhibited reduced frequency of firing to mechanical stimuli. Thus, p75 regulates normal mechanotransduction in both nociceptive and non-nociceptive neurons as well as in neurons with both slowly and rapidly adapting properties. Although NGF mediates the survival (Crowley et al., 1994) and phenotype (Lewin and Mendell, 1994) of C fibers, the effect of p75 on the mechanical function of $\mathrm{C}$ fibers is not likely mediated by NGF. First, sequestration of endogenous NGF in neonatal rats results in $\mathrm{C}$ fibers that are very sensitive to mechanical stimuli (Lewin and Mendell, 1994) and, second, sequestration of NGF in adult animals leaves mechanical responsiveness unchanged (Koltzenburg et al., 1996). Furthermore, sequestration of endogenous NGF in either neonatal or adult rats results in $\mathrm{C}$ fibers with significantly reduced heat sensitivity (Lewin and Mendell, 1994; Koltzenburg et al., 1996). However, C fibers in p $75-/-$ mice had normal heat sensitivity. Thus, p75 regulates the mechanical sensitivity of $\mathrm{C}$ fibers through an NGF-independent mechanism, and p75 is not involved in the regulation of the sensitivity of $\mathrm{C}$ fibers to heat.

It is not known which ligand(s) activates the p75 receptor to modulate the mechanical sensitivity of D-hair receptors. The ligand is unlikely to be NGF, BDNF, or NT-3, because D-hair receptors in animals that lack each of these neurotrophins, respectively, are normal in mechanical function (Ritter et al., 1991; Koltzenburg et al., 1995; Airaksinen et al., 1996). One possibility is that the ligand is NT-4. Retrograde transport of NT-4 in p75-/- mice is reduced more severely than is transport of the other neurotrophins (Curtis et al., 1995). In addition, we found that in transgenic mice that lack NT-4, D-hair receptors are almost completely absent (Stucky et al., 1996). This could mean that NT-4 is required to mediate the survival of D-hair receptors by binding to trk receptors, whereas the presence of p75 is necessary to mediate NT-4-dependent function of D-hair receptors.

The cellular mechanisms underlying p75-mediated survival and function are not yet clear. Because p 75 has been proposed to be involved in several signal transduction pathways, p75 may mediate cell survival and function through different mechanisms. p75 has been shown to interact directly with trk receptors by increasing the local concentration of a neurotrophin in the vicinity of its cognate trk receptor (Barker and Shooter, 1994), by increasing autophosphorylation of the trk receptors (Berg et al., 1991; Verdi et al., 1994), or by enhancing the discrimination of the trk receptors for their preferred ligands (Rodríguez Tébar et al., 1992; Benedetti et al., 1993). Alternatively, p75 may signal directly, either by stimu- lating production of ceramide through activation of sphingomyelin (Dobrowsky et al., 1994, 1995) or by activating the transcription factor $\mathrm{NF} \kappa \mathrm{B}$ (Carter et al., 1996). A recent study has shown that $\mathrm{NF}_{\kappa} \mathrm{B}$ is not active in the developing mouse until after birth, suggesting that $\mathrm{NF} \kappa \mathrm{B}$ does not play a role in developing and differentiating tissue, but instead maintains the function of tissue once it has matured (Schmidt-Ullrich et al., 1996). Thus, an intriguing possibility is that the $\mathrm{p} 75-\mathrm{NF} \kappa \mathrm{B}$ pathway may regulate the p75-dependent function of sensory neurons.

Future studies are necessary to sort out the specific pathways involved in neuronal survival and function. Studies that determine when the p75-dependent neuronal loss occurs during embryogenesis in p75-/- animals may illuminate mechanisms underlying the cell loss. Moreover, mechanical sensitivity is not the only sensory function modulated by $\mathrm{p} 75$ in unmyelinated nociceptors. A recent study has shown that the expression of bradykinin receptors on presumptive nociceptors in culture is mediated by a specific interaction between NGF and p75 (Petersen et al., 1996), demonstrating that p75 also modulates chemosensitivity.

Knowledge about the role of p75 in regulating the sensitivity of nociceptors has important clinical implications. First, because increased sensitivity of nociceptors occurs in chronic pain states (Koltzenburg, 1996), reversing the increased excitability could lead to the development of novel analgesics. Second, the function of sensory neurons is typically impaired in polyneuropathies. For example, in patients with diabetic polyneuropathy, reduced levels of neurotrophins in tissue correlate with the functional deficits (Anand, 1996). Thus, knowledge of mechanisms that compromise neurotrophin signaling may advance the understanding of the pathobiology and treatment of this prevalent neurodegenerative disease.

\section{REFERENCES}

Airaksinen MS, Koltzenburg M, Lewin GR, Masu Y, Helbig C, Wolf E, Brem G, Toyka KV, Thoenen H, Meyer M (1996) Specific sub-types of cutaneous mechanoreceptors require neurotrophin-3 following peripheral target innervation. Neuron 16:287-295.

Albers KM, Perrone TN, Goodness TP, Jones ME, Green MA, Davis BM (1996) Cutaneous overexpression of NT-3 increases sensory and sympathetic neuron number and enhances touch dome and hair follicle innervation. J Cell Biol 134:487-497.

Anand P (1996) Neurotrophins and peripheral neuropathy. Philos Trans R Soc Lond [Biol] 351:449-454.

Averill S, McMahon SB, Clary DO, Reichardt LF, Priestley JV (1995) Immunocytochemical localization of trkA receptors in chemically identified subgroups of adult rat sensory neurons. Eur J Neurosci 7:1484-1494. 
Barbacid M (1994) The Trk family of neurotrophin receptors. J Neurobiol 25:1386-1403.

Barker PA, Shooter EM (1994) Disruption of NGF binding to the low affinity neurotrophin receptor p75LNTR reduces NGF binding to TrkA on PC12 cells. Neuron 13:203-215.

Benedetti M, Levi A, Chao MV (1993) Differential expression of nerve growth factor receptors leads to altered binding affinity and neurotrophin responsiveness. Proc Natl Acad Sci USA 90:7859-7863.

Bennett DLH, McMahon SB, Shelton D, Koltzenburg M (1996) NGF sequestration using a trkA-IgG fusion molecule prevents primary afferent sensitisation to carrageenan inflammation. 8th World Congress Pain Abstr 8:120.

Berg MM, Sternberg DW, Hempstead BL, Chao MV (1991) The lowaffinity p75 nerve growth factor (NGF) receptor mediates NGF-induced tyrosine phosphorylation. Proc Natl Acad Sci USA 88:7106-7110.

Bergmann I, Priestley JV, McMahon SB, Bröker EB, Toyka KV, Koltzenburg M (1997) Analysis of cutaneous sensory neurones in transgenic mice lacking the low affinity neurotrophin receptor p75. Eur J Neurosci 9:18-28.

Carroll SL, Silos-Santiago I, Frese SE, Ruit KG, Milbrandt J, Snider WD (1992) Dorsal root ganglion neurons expressing trk are selectively sensitive to NGF deprivation in utero. Neuron 9:779-788.

Carter BD, Kaltschmidt C, Kaltschmidt B, Offenhäuser N, BöhmMatthaei R, Baeuerle PA, Barde YA (1996) Selective activation of $\mathrm{NF} \kappa \mathrm{B}$ by nerve growth factor through the neurotrophin receptor $\mathrm{p} 75$. Science 272:542-545.

Crowley C, Spencer SD, Nishimura MC, Chen KS, Pitts-Meek S, Armanini MP, Ling LH, McMahon SB, Shelton DL, Levinson AD, Phillips HS (1994) Mice lacking nerve growth factor display perinatal loss of sensory and sympathetic neurons yet develop basal forebrain cholinergic neurons. Cell 76:1001-1011.

Curtis R, Adryan KM, Stark JL, Park JS, Compton DL, Weskamp G, Huber LJ, Chao MV, Jaenisch R, Lee KF, Lindsay RM, DiStefano PS (1995) Differential role of the low affinity neurotrophin receptor $(\mathrm{p} 75)$ in retrograde axonal transport of the neurotrophins. Neuron 14:1201-1211.

Diamond J, Lourenssen S, Pertens E, Urschel B (1995) Lack of collateral sprouting of nociceptive nerves in adult p75 knock-out mice. Soc Neurosci Abstr 21:1539.

Dobrowsky RT, Werner MH, Castellino AM, Chao MV, Hannun YA (1994) Activation of the sphingomyelin cycle through the low-affinity neurotrophin receptor. Science 265:1596-1599.

Dobrowsky RT, Jenkins GM, Hannun YA (1995) Neurotrophins induce sphingomyelin hydrolysis. Modulation by co-expression of p75NTR with Trk receptors. J Biol Chem 270:22135-22142.

Ernfors P, Lee KF, Kucera J, Jaenisch R (1994) Lack of neurotrophin-3 leads to deficiencies in the peripheral nervous system and loss of limb proprioceptive afferents. Cell 77:503-512.

Fariñas I, Jones KR, Backus C, Wang XY, Reichardt LF (1994) Severe sensory and sympathetic deficits in mice lacking neurotrophin-3. Nature 369:658-661

Forster C, Handwerker HO (1990) Automatic classification and analysis of microneurographic spike data using a PC/AT. J Neurosci Methods 31:109-118.

Hallböök F, Ibáñez CF, Persson H (1991) Evolutionary studies of the nerve growth factor family reveal a novel member abundantly expressed in Xenopus ovary. Neuron 6:845-858.

Hempstead BL, Martin-Zanca D, Kaplan DR, Parada LF, Chao MV (1991) High-affinity NGF binding requires coexpression of the trk proto-oncogene and the low-affinity NGF receptor. Nature 350:678-683.

Klein R, Silos-Santiago I, Smeyne RJ, Lira SA, Brambilla R, Bryant S, Zhang L, Snider WD, Barbacid M (1994) Disruption of the neurotrophin-3 receptor gene trkC eliminates la muscle afferents and results in abnormal movements. Nature 368:249-251.

Koltzenburg M (1996) Stability and plasticity of nociceptor function and their relationship to provoked and ongoing pain. Semin Neurosci 7:199-210.

Koltzenburg M, Lewin GR, Toyka KV, Thoenen H, Carroll P (1995) Electrophysiological analysis of cutaneous sensory neurons in neonatal wild type mice and transgenic animals lacking BDNF. Soc Neurosci Abstr 21:154.

Koltzenburg M, Bennett DLH, Shelton DL, Toyka KV, McMahon SB (1996) Sequestration of endogenous nerve growth factor (NGF) in adult rat reduces the sensitivity of nociceptors. 8th World Congress Pain Abstr 8:120.
Kress M, Koltzenburg M, Reeh PW, Handwerker HO (1992) Responsiveness and functional attributes of electrically localized terminals of cutaneous C-fibers in vivo and in vitro. J Neurophysiol 68:581-595.

Lee K-F, Li E, Huber LJ, Landis SC, Sharpe AH, Chao MV, Jaenisch R (1992) Targeted mutation of the gene encoding the low affinity NGF receptor p75 leads to deficits in the peripheral sensory nervous system. Cell 69:737-749.

Lee K-F, Davies AM, Jaenisch R (1994) p75-Deficient embryonic dorsal root sensory and neonatal sympathetic neurons display a decreased sensitivity to NGF. Development 120:1027-1033.

Lee K-F, Dickinson-Anson H, Gage FH, Byers M (1995) Low-affinity neurotrophin receptor $\mathrm{p} 75$ is required for the development of some mechanoreceptors. Soc Neurosci Abstr 21:1056.

Lewin GR, Mendell LM (1994) Regulation of cutaneous C-fiber heat nociceptors by nerve growth factor in the developing rat. J Neurophysiol 71:941-949.

Lewin GR, Ritter AM, Mendell LM (1992) On the role of nerve growth factor in the development of myelinated nociceptors. J Neurosci 12:1896-1905.

McMahon SB, Armanini MP, Ling LH, Phillips HS (1994) Expression and coexpression of Trk receptors in subpopulations of adult primary sensory neurons projecting to identified peripheral targets. Neuron 12:1161-1171.

Meyer RA, Campbell JN (1981) Myelinated nociceptive afferents account for the hyperalgesia that follows a burn to the hand. Science 213:1527-1529.

Mu X, Silos-Santiago I, Carroll SL, Snider WD (1993) Neurotrophin receptor genes are expressed in distinct patterns in developing dorsal root ganglia. J Neurosci 13:4029-4041.

Petersen M, Segond von Banchet G, Heppelmann B, Koltzenburg M (1996) NGF selectively regulates bradykinin binding sites in adult sensory neurons via the neurotrophin receptor p75. Soc Neurosci Abstr 22:747.

Radeke MJ, Misko TP, Hsu C, Herzenberg LA, Shooter EM (1987) Gene transfer and molecular cloning of the rat nerve growth factor receptor. Nature 325:593-597.

Ritter AM, Lewin GR, Kremer NE, Mendell LM (1991) Requirement for nerve growth factor in the development of myelinated nociceptors in vivo. Nature 350:500-502.

Rodríguez Tébar A, Dechant G, Barde YA (1990) Binding of brainderived neurotrophic factor to the nerve growth factor receptor. Neuron 4:487-492.

Rodríguez Tébar A, Dechant G, Götz R, Barde YA (1992) Binding of neurotrophin-3 to its neuronal receptors and interactions with nerve growth factor and brain-derived neurotrophic factor. EMBO J 11:917-922.

Rueff A, Mendell LM (1995) NGF-induced increase in thermal sensitivity of nociceptive fibers in vitro. Soc Neurosci Abstr 21:1537.

Ruit KG, Elliott JL, Osborne PA, Yan Q, Snider WD (1992) Selective dependence of mammalian dorsal root ganglion neurons on nerve growth factor during embryonic development. Neuron 8:573-587.

Schecterson LC, Bothwell M (1992) Novel roles for neurotrophins are suggested by BDNF and NT-3 mRNA expression in developing neurons. Neuron 9:449-463.

Schmidt-Ullrich R, Mémet S, Lilienbaum A, Feuillard J, Raphaël M, Israël A (1996) NF $\kappa$ B activity in transgenic mice: developmental regulation and tissue specificity. Development 122:2117-2128.

Smeyne RJ, Klein R, Schnapp A, Long LK, Bryant S, Lewin A, Lira SA, Barbacid M (1994) Severe sensory deficits and sympathetic neuropathies in mice carrying a disrupted Trk/NGF receptor gene. Nature 368:246-249.

Stucky CL, Koltzenburg M, DeChiara T, Lindsay RM, Yancopoulos GD (1996) Neurotrophin-4 (NT-4) is required for the development of a subclass of cutaneous sensory neurons. Soc Neurosci Abstr 22:992.

Tal M, Schneider M, Toyka KV, Koltzenburg M (1996) Heat hyperalgesia and nociceptor excitation after application of nerve growth factor (NGF) or inflammatory mediators. 8th World Congress on Pain Abstr:119.

Thalhammer JG, LaMotte RH (1982) Spatial properties of nociceptor sensitization following heat injury of the skin. Brain Res 231:257-265.

Verdi JM, Birren SJ, Ibáñez CF, Persson H, Kaplan DR, Benedetti M, Chao MV, Anderson DJ (1994) p75LNGFR regulates Trk signal transduction and NGF-induced neuronal differentiation in MAH cells. Neuron 12:733-745.

Wright DE, Snider WD (1995) Neurotrophin receptor mRNA expression defines distinct populations of neurons in rat dorsal root ganglia. J Comp Neurol 351:329-338. 